\title{
ANALISIS USAHATANI AREN (Arenga pinnata Merr) DI KOTA TOMOHON, SULAWESI UTARA
}

\author{
The Analysis of Aren Farming (Arenga pinnata Merr) in Tomohon City, \\ North Sulawesi
}

\author{
Alfred P. Manambangtua*, Ronald T.P. Hutapea, Jerry Wungkana \\ Balai Penelitian Tanaman Palma, Manado \\ ${ }^{*}$ Kontak penulis: alfredpahala@gmail.com
}

\begin{abstract}
Aren (Arenga pinnata Merr) is a type of palm that has a fairly high economic value, is spreading widely in Indonesia. All parts of the sugar plant ranging from leaves to roots can be utilized. The main result is the sap of the sugar plant, sugar palm juice contains between $10-15 \%$. Because the sugar content of the sugar palm can be processed into alcohol, palm sugar, palm syrup, palm vinegar and ethanol. Based on the analysis results obtained, sugar palm farmers monthly fee of Rp. 2,196,815, - and Rp 26361 780, - per year. Average monthly revenues of Rp 4.1236 million, - and Rp 49.483.200, - per year. Palm farmers' income of $\mathrm{Rp}$ 1,926,785, - and Rp 23.121.420, - per year. Analysis of R / C Ratio > 1 is 1.88, which means businesses aren farmer in Tomohon is getting profit.
\end{abstract}

Keywords : revenue; income; cost; aren farmers.

Sitasi: Manambangtua, A.P., R.T.P. Hutapea, J. Wungkana, 2018. Analisis Usahatani Aren (Arenga pinnata Merr) di Kota Tomohon, Sulawesi Utara, JSEP 14(1): 85 - 92.

\section{Pendahuluan}

Aren (Arenga pinnata Merr) merupakan jenis palma yang memiliki nilai ekonomis yang cukup tinggi, penyebarannya sangat luas di Indonesia. Semua bagian dari tanaman aren mulai dari daun sampai akar dapat dimanfaatkan. Produkproduk unggulan aren sebagai sumber pangan dan energi antara lain gula merah, gula semut, nira segar, kolang-kaling, dan minuman beralkohol. Selain itu produkproduk aren banyak digunakan untuk bahan kerajinan, maupun bahan bangunan.

Pohon aren kebanyakan tumbuh secara liar, baik di dataran rendah, lereng bukit, lembah, maupun pegunungan hingga ketinggian 1.400 meter dpl. Akar tanaman aren bisa mencapai kedalaman 6-8 meter, sangat potensial untuk menahan erosi dan air (Widyawati, 2011).

Pada tahun 2013 luas tanaman Aren di Indonesia sebesar 99.251.859 ha, tanaman ini diusahakan atau dikelola oleh perkebunan rakyat (BPS, 2013). Dengan total produksi untuk tahun 2011 sebesar 42.189 ton setara gula merah yang berasal dari perkebunan rakyat (Statistik Perkebunan, 2009-2011). Sulawesi Utara merupakan propinsi yang memiliki luas tanaman aren yang terbesar di Indonesia dengan luas 30.645,772 ha (BPS, 2013). Salah datu daerah yang menjadi sentra tanaman aren di Sulawesi Utara adalah Kota Tomohon.

Hasil utama dari tanaman aren adalah nira. Nira adalah cairan yang disadap dari bunga jantan pohon aren, yang tidak lain adalah hasil metabolisme dari pohon tersebut. Cairan yang disebut nira aren ini mengandung gula antara 10-15\%. Karena 
kandungan gulanya tersebut maka nira aren dapat diolah menjadi minuman beralkohol, gula aren, gula semut, sirup aren, cuka aren, nata de arenga dan etanol (Widyawati, 2011).

Di Kota Tomohon konsumsi minuman beralkohol yang bersumber dari pohon aren cukup tinggi. Umumnya masyarakat mengkonsumsinya sebagai bagian dari upaya untuk penyesuaian tubuh dengan hawa dingin. Selain itu, di Kota Tomohon berkembang unit-unit usaha pembuatan gula aren berskala rumah tangga, upaya untuk memproduksi gula semut juga telah ditempuh masyarakat. Produk turunan dari gula aren dalam bentuk kue-kue khas dari Tomohon juga dikembangkan sebagai sumber ekonomi masyarakat. Selain fungsinya pada dimensi ekonomi, eksistensi pohon aren di Kota Tomohon juga menjadi urgen karena efektif dalam menahan erosi dimana geografi Kota Tomohon cenderung bertebing.

Beberapa permasalahan yang dihadapi petani dan pengolah aren skala rumah tangga di Kota Tomohon adalah umumnya tanaman aren berupa tanaman hutan dan sebagian besar belum dibudidayakan. Ini menyebabkan produk nira dari pohon aren bervariasi antar pohon dan cenderung rendah. Dari sisi manajemen usaha, kebanyakan petani aren tidak mampu berkembang atau bersaing karena sering terbentur masalah modal, ini menyebabkan aren yang diusahakan rakyat sering mengalami penurunan produksi. Dengan permasalahan demikian menjadi pertanyaan sampai mana sebenarnya nilai ekonomi yang diperoleh petani dari produk aren. Berbagai penelitian tentang analisis usahatani sebuah komoditas pertanian telah dilakukan, misalnya Hasibuan (2014) untuk jagung, Laelani (2011) untuk kelapa sawit, Maryam (2012) untuk aglaonema, dan Supartama et.al (2013) untuk padi sawah, namun analisis usahatani untuk komoditas gula aren masih terbatas dilakukan (Saleh, 2014). Berdasarkan latar masalah dan kondisi hasil-hasil penelitian tersebut maka tulisan ini menyajikan hasil penelitian tentang analisis usahatani atas gula aren.

\section{Metode Penelitian}

Lokasi penelitian ditentukan secara sengaja (purposive) di wilayah Kota Tomohon yakni Desa Kayau dan Desa Tara-tara. Lokasi ini dipilih karena populasi pohon aren dan rumah tangga yang mengusahakan gula aren pada kedua desa tersebut cukup besar.

Data dikumpulkan melalui wawancara menggunakan kuesioner. Data primer yang dikumpulkan mencakup identitas petani, komponen biaya dalam usahatani, penerimaan usahatani, pendapatan usahatani serta jenis produk yang dihasilkan dari usaha aren. Data dikumpulkan dari 20 petani sebagai sampel dalam penelitian ini.

Analisa data mencakup analisis penerimaan usahatani, analisis biaya usahatani dan analisis kelayakan usahatani. Komponen analisis masing-masing diuraikan, sebagai berikut:

a. Penerimaan usahatani, dihitung dengan rumus (Shinta, 2011):

$$
T R=P y . Y
$$

Keterangan : TR $=$ Total Penerimaan

Py $=$ Harga Produk

$\mathrm{Y}=$ Produksi yang diperoleh 
b. Biaya produksi usahatani dihitung dengan rumus:

$$
T C=F C+V C
$$

Keterangan $: \mathrm{TC}=$ Total Biaya Produksi

$\mathrm{FC}=$ Biaya Tetap

$\mathrm{VC}=$ Biaya tidak Tetap

c. Pendapatan usahatani dihitung dengan rumus:

$$
I=T R-T C
$$

Keterangan: $\mathrm{I}=$ Pendapatan (Income)

$\mathrm{TR}=$ Total Penerimaan

$\mathrm{TC}=$ Total Biaya

d. Kelayakan usahatani dihitung dengan Return Cost Ratio (R/C)

$$
R / C
$$

Keterangan $: \mathrm{R}=$ Py. $\mathrm{Y}$ (Revenue $=$ Penerimaan usaha tani)

$\mathrm{C}=\mathrm{FC}+\mathrm{VC}($ Cost $=$ Biaya produksi usaha tani $)$

Jika $\mathrm{R} / \mathrm{C} \geq 1$ = Maka Usaha Tani Layak diusahakan

$\mathrm{R} / \mathrm{C}<1=$ Maka Usaha Tani Tidak Layak diusahakan

\section{Hasil dan Pembahasan}

\section{Karakteristik Petani}

\section{Umur Petani}

Dalam berusahatani, umur sangat berperan penting dalam setiap aktivitas yang berhubungan dengan tingkat kemampuan fisik. Dari hasil penelitian didapatkan hasil rata-rata umur petani bekisar 48,9 tahun. Petani aren di Tomohon sebagian besar merupakan petani yang berusia produktif (15 - 64 tahun) yaitu sebesar $90 \%$ dan hanya $10 \%$ yang berada dalam kisaran umur kurang produktif ( > 64 tahun). Dengan struktur umur tersebut, petani aren di Kota Tomohon mampu melakukan kegiatan penyadapan aren. Kegiatan penyadapan membutuhkan kondisi fisik yang prima, karena harus berjalan masuk hutan melewati jalan kebun serta menggunakan sejumlah peralatan untuk melakukan penyadapan. Umur petani akan mempengaruhi kemampuan fisik bekerja, jika semakin tinggi umur seseorang setelah melewati batas umur tertentu, maka makin berkurang kemampuan berprestasi sebagai tenaga kerja dan petani yang masih muda dan sehat mempunyai tenaga yang lebih besar dari pada petani yang sudah tua (Ruauw, 2011).

\section{Tabel 1}

Jumlah Petani Aren Sampel Berdasarkan Umur di Kota Tomohon, Sulawesi Utara

\begin{tabular}{cccc}
\hline No. & $\begin{array}{c}\text { Kelompok Umur } \\
\text { (tahun) }\end{array}$ & $\begin{array}{c}\text { Jumlah } \\
\text { (orang) }\end{array}$ & $\begin{array}{c}\text { Pesentase } \\
\mathbf{( \% )}\end{array}$ \\
\hline 1 & $<15$ & 0 & 0 \\
2 & $15-64$ & 18 & 90 \\
3 & $>64$ & 2 & 10 \\
\hline & Jumlah & $\mathbf{2 0}$ & $\mathbf{1 0 0}$ \\
\hline
\end{tabular}




\section{Tingkat Pendidikan Petani}

Tingkat pendidikan petani dapat mempengaruhi cara petani mengambil keputusan dan memecahkan masalah yang dihadapi dalam mengelola dan mengembangkan usahataninya dan mempengaruhi juga terhadap kemampuan petani dalam menerapkan informasi baru berupa inovasi dan ilmu pengetahuan. Tingkat pendidikan petani dapat dilihat pada Tabel 2.

Tabel 2

Jumlah Petani Aren Sampel Berdasarkan Tingkat Pendidikan di Kota Tomohon, Sulawesi Utara

\begin{tabular}{llcc}
\hline No & Tingkat Pendidikan & $\begin{array}{c}\text { Jumlah } \\
\text { (orang) }\end{array}$ & $\begin{array}{c}\text { Pesentase } \\
\text { (\%) }\end{array}$ \\
\hline 1 & Tidak Sekolah/Tidak Tamat SD & 4 & 20 \\
2 & SD & 9 & 45 \\
3 & SLTP & 5 & 25 \\
4 & SLTA & 2 & 10 \\
\hline & & Jumlah & $\mathbf{2 0}$ \\
\hline
\end{tabular}

Tabel 2 menunjukkan data bahwa tingkat pendidikan formal yang pernah dijalani oleh petani aren sampel di Kota Tomohon sebagian besar atau sebesar 45\% adalah tamatan Sekolah Dasar, sedangkan tingkat SLTP sebesar 25\%. Petani yang tidak pernah mengenyam pendidikan formal dan tidak tamat SD sebesar $20 \%$. Hanya sebagian kecil atau sebesar $10 \%$ yang telah menamatkan pendidikan formalnya di tingkat SLTA. Rendahnya tingkat pendidikan petani aren di Kota Tomohon dapat disebabkan oleh masih rendahnya tingkat kesadaran untuk melanjutkan pendidikan ke tingkat yang lebih tinggi dan faktor ekonomi petaninya yang masih rendah. Hal ini juga terkait dengan kemampuan petani dalam menerapkan informasi baru dalam bidang petanian dan membantu petani dalam mengambil keputusan serta dalam memecahkan masalah yang dihadapi petani dalam mengelola usaha taninya (Wijayanti, 2012).

\section{Pengalaman Petani}

Petani aren dengan pengalaman yang mamadai tentunya akan mampu lebih efisien dan produktif dalam mengelola usahataninya. Dari pengalamannya tersebut, seorang petani dapat mengambil pelajaran penting untuk memperbaiki praktik dan mengembangkan usahatani yang dikelolanya. Tabel 3 menunjukkan jumlah petani aren sampel di Kota Tomohon berdasarkan pengalamannya berusahatani aren. Data pada Tabel 3 menunjukkan bahwa sebagian besar atau sebesar $45 \%$ dari petani aren sampel memiliki pengalaman pada kisaran 11 - 20 tahun. Hanya terdapat sebesar $10 \%$ petani aren yang memiliki pengalaman dalam kisaran 31 - 40 tahun. Berdasarkan lama pengalaman berusahatani ini, petani aren akan cenderung tahu dan mampu mengatasi permasalahan yang dihadapi dalam pengelolaan dan pengembangan usahataninya. 
Tabel 3

Jumlah Petani Aren Sampel Berdasarkan Pengalaman di Kota Tomohon, Sulawesi Utara

\begin{tabular}{cccc}
\hline No. & $\begin{array}{c}\text { Pengalaman petani } \\
\text { (tahun) }\end{array}$ & $\begin{array}{c}\text { Jumlah } \\
\text { (orang) }\end{array}$ & $\begin{array}{c}\text { Pesentase } \\
\text { (\%) }\end{array}$ \\
\hline 1 & $0-10$ & 4 & 20 \\
2 & $11-20$ & 9 & 45 \\
3 & $21-30$ & 5 & 25 \\
4 & $31-40$ & 2 & 10 \\
\hline & Jumlah & $\mathbf{2 0}$ & $\mathbf{1 0 0}$ \\
\hline
\end{tabular}

\section{Biaya Usahatani}

Setiap melakukan suatu usaha tentunya mengeluarkan biaya-biaya yang digunakan untuk membiayai proses produksi usaha tersebut. Biaya-biaya dibagi menjadi dua jenis, yaitu biaya tetap (fixed cost) dan biaya variabel (variable cost). Biaya tetap adalah biaya yang tidak bertambah seiring dengan pertambahan produksi sedangkan biaya variabel adalah biaya yang bertambah seiring dengan pertambahan produksi. Hasil penelitian menunjukkan biaya tetap yang dikeluarkan oleh petani aren sampel di Kota Tomohon adalah biaya penyusutan alat, sedangkan biaya variabel meliputi biaya bahan penolong, kayu bakar, dan upah tenaga kerja. Tabel 4 menunjukkan analisis biaya usahatani gulan aren di Kota Tomohon dalam per bulan dan per tahun.

Tabel 4

Biaya Usahatani Petani Aren di Kota Tomohon, Sulawesi Utara

\begin{tabular}{|c|c|c|c|}
\hline No. & Jenis Biaya & $\begin{array}{c}\text { Nilai/Bulan } \\
\text { (Rp) }\end{array}$ & $\begin{array}{c}\text { Nilai/Tahun } \\
\text { (Rp) }\end{array}$ \\
\hline 1 & Biaya Variabel & 2.166 .900 & 26.002 .800 \\
\hline \multirow[t]{2}{*}{2} & Biaya Tetap & 29.915 & 358.980 \\
\hline & Jumlah & 2.196 .815 & 26.361 .780 \\
\hline
\end{tabular}

Hasil analisis biaya usahatani aren oleh petani aren di Kota Tomohon menunjukkan bahwa total biaya yang dikeluarkan sebesar Rp 2.196.815,- selama satu bulan produksi atau sebesar Rp 26.361.780,- selama satu tahun produksi. Berdasarkan data yang ditampilkan Tabel 4 menunjukkan bahwa struktur biaya usahatani aren terdiri dari biaya tetap sebesar 1,4\% dan biaya variabel sebesar $98,6 \%$.

\section{Penerimaan Petani}

Besar kecilnya penerimaan yang diperoleh dari suatu usaha dipengaruhi oleh besar kecilnya produksi dan harga yang berlaku. Untuk meningkatkan penerimaan tentunya petani aren mengoptimalkan produksi yaitu dengan cara meningkatkan 
produksi niranya. Sedangkan dari segi harga lebih tergantung dari harga pasar yang berlaku (Saleh, 2014). Penerimaan dari usahatani aren oleh petani aren di Kota Tomohon dapat dilihat pada data yang ditampilkan Tabel 5. Dari data tersebut menunjukan bahwa rata-rata penerimaan per bulan petani aren di Kota Tomohon sebesar Rp. 4.123.600,- dan rata-rata penerimaan pertahun sebesar Rp 49.483.200,-.

Tabel 5

Penerimaan Usaha Petani Aren di Kota Tomohon, Sulawesi Utara

\begin{tabular}{ccc}
\hline No. & Uraian & $\begin{array}{c}\text { Nilai } \\
\mathbf{( R p})\end{array}$ \\
\hline 1. & Rata-Rata Penerimaan per Bulan & 4.123 .600 \\
2. & Rata-Rata Penerimaan per Tahun & 49.483 .200 \\
\hline
\end{tabular}

\section{Pendapatan Petani}

Pendapatan merupakan selisih antara total penerimaan yang diperoleh dengan total biaya yang dikeluarkan selama proses produksi. Untuk pendapatan yang diperoleh petani aren di Kota Tomohon dapat dilihat pada Tabel 6.

Tabel 6

Pendapatan Petani Aren di Kota Tomohon, Sulawesi Utara

\begin{tabular}{clccc}
\hline No. & & Uraian & $\begin{array}{c}\text { Nilai/Bulan } \\
(\mathbf{R p})\end{array}$ & $\begin{array}{c}\text { Nilai/Tahun } \\
(\mathbf{R p})\end{array}$ \\
\hline 1 & Penerimaan & 4.123 .600 & 49.483 .200 \\
2 & Biaya & 2.196 .815 & 26.361 .780 \\
\hline & Pendapatan (Penerimaan - Biaya) & $\mathbf{1 . 9 2 6 . 7 8 5}$ & $\mathbf{2 3 . 1 2 1 . 4 2 0}$ \\
\hline
\end{tabular}

Berdasarkan Tabel 6 dapat dilihat bahwa pendapatan petani aren di Kota Tomohon sebesar Rp 1.926.785,- per bulan dan memperoleh pendapatan per tahunya sebesar Rp 23.121.420,--

\section{Kelayakan Usaha Tani}

$R / C$ ratio adalah singkatan dari Return Cost Ratio, atau dikenal sebagai perbandingan (nisbah) antara penerimaan dan biaya. Secara teoritis dengan rasio $R / C$ $=1$ artinya tidak untung dan tidak rugi, jika nilai $R / C>1$ usahatani yang dilakukan adalah layak, sedangkan jika $R / C<1$, maka usahatani yang dilakukan dikategorikan tidak layak. Hasil analisis $R / C$ Ratio usaha aren di Kota Tomohon secara rinci ditampilkan pada Tabel 7. Berdasarkan perhitungan $R / C$ rasio pada usaha petani aren di Tomohon dapat disimpulkan bahwa usaha tani aren layak untuk diusahakan, karena nilai $R / C$ rasionya lebih besar dari satu atau $R / C>1$. 
Tabel 7

Analisis R/C Ratio Pada Usaha Petani Aren di Kota Tomohon, Sulawesi Utara

\begin{tabular}{clc}
\hline \multirow{2}{*}{ No. } & Uraian & $\begin{array}{c}\text { Nilai/Bulan } \\
\mathbf{( R p )}\end{array}$ \\
\hline 1 & Penerimaan & 4.123 .600 \\
2 & Biaya & 2.196 .815 \\
\hline & R/C Ratio (Penerimaan/Biaya) & $\mathbf{1 , 8 8}$ \\
\hline
\end{tabular}

\section{Bentuk Produk yang Dihasilkan}

Petani aren di Kota Tomohon tidak semua mengolah nira hasil sadapan menjadi gula aren. Ada beberapa petani yang mengolah nira menjadi gula semut, minuman beralkohol atau yang menjual nira sadapan secara langsung kepada pengolah gula semut.

Gula aren mempunyai kekhasan, yakni mudah larut dan mempunyai aroma yang khas, apabila dibanding dengan gula tebu. Oleh sebab itu, gula aren banyak digunakan dalam pembuatan berbagai macam makanan terutama kue-kue. Bahan dasar gula aren berasal dari nira yang masih segar, memiliki rasa yang manis, tidak berwarna dan memiliki $p H$ 6-7. Gula aren diperoleh dengan cara memasak nira segar hasil sadapan sampai kental dan berwarna coklat kemerahan. Dalam proses pemasakan selalu dilakukan pengadukan untuk mencegah agar nira tidak meluap (Anonimus, 2013). Di kota Tomohon, petani pengolah gula aren dalam mencegah agar nira tidak meluap selain melakukan pengadukan mereka juga memberi sedikit minyak kelapa. Setelah nira menjadi kental, selanjutnya diangkat dan siap dituangkan ke dalam cetakan. Cetakan dapat terbuat dari setengah tempurung kelapa, bambu atau cetakan dari kayu.

Produk gula semut adalah gula aren berbentuk serbuk, beraroma khas, dan berwarna kuning kecoklatan. Proses pengolahan gula semut sama dengan pengolahan gula cetak. Pada pengolahan gula semut setelah diperoleh nira kental, dilanjutkan dengan pendinginan dan pengkristalan. Pengkristalan dilakukan dengan cara pengadukan menggunakan garpu kayu. Pengadukan dilakukan secara perlahan-lahan, dan makin lama makin cepat hingga terbentuk serbuk gula (Mashud, 2012).

Produk minuman beralkohol adalah produk air nira melalui proses fermentasi. Untuk pengolahan nira aren menjadi alkohol, biasanya nira akan dibiarkan terfermentasi 1 - 2 hari agar didapat kandungan etanol yang tinggi. Rasa nira akan berubah dari manis menjadi asam. Setelah terfermentasi, nira aren akan mengalami proses destilasi secara sederhana. Biasanya tungku pemasakan menggunakan drum bekas, sedangkan pipa-pipa uap menggunakan bambu yang disusun sedemikian rupa sehingga dapat mengembunkan uap panas yang mengadung etanol. Di Sulawesi Utara minuman beralkohol yang berasal dari nira aren ini lebih dikenal dengan nama Cap Tikus. Walaupun peredarannya di masyarakat dilarang pemerintah, namun karena permintaannya tinggi maka petani aren masih memproduksinya. 


\section{Kesimpulan}

Total biaya yang dikeluarkan oleh petani aren di Kota Tomohon selama satu bulan produksi adalah Rp 2.196.815,- dan biaya yang dikeluarkan selama satu tahun produksi sebesar Rp 26.361.780,-. Dari total biaya tersebut diperoleh penerimaan per bulan sebesar $\operatorname{Rp}$ 4.123.600,- dan rata-rata penerimaan per tahun sebesar Rp 49.483.200,-. Berdasarkan biaya dan penerimaan tersebut, diperoleh pendapatan sebesar Rp 1.926.785,- per bulan dan pendapatan per tahunnya sebesar Rp 23.121.420,-. Nilai $R / C$ ratio diperoleh $>1$, sehingga usahatani aren dinilai layak untuk diusahakan.

\section{Daftar Pustaka}

Anonimus, 2013. Pedoman Budidaya Aren (Arenga pinnata MERR) yang Baik. (Lampiran Peraturan Menteri Pertanian Republik Indonesia Nomor 133/Permentan/OT. 140/12/2013. Tentang Pedoman Budidaya Aren (Arenga pinnata MERR) yang Baik). Jakarta: Departemen Pertanian.

BPS, 2013. Data Sensus Pertanian. Jakarta: BPS.

Hasibuan, H., 2014. Analisis Biaya dan Pendapatan Usahatani Jagung Hibrida Panen Muda dan Panen Tua serta Faktor-Faktor yang Mempengaruhi Pendapatan (Studi Kasus di Nagari Sungai Talang Kecamatan Guguak Kabupaten Lima Puluh Kota) [Skripsi]. Payakumbuh: Fakultas Pertanian Universitas Muhammadiyah Sumatera Barat.

Laelani, A., 2011. “Analisis Usaha Tani Kelapa Sawit di Desa Hampalit Kecamatan Katingan Hilir Kabupaten Katingan”. Ziraa'ah, Volume 32, Nomor 3: 225 - 230.

Maryam, S., 2012. Analisis Pendapatan dan Efisiensi Usahatani Aglaonema (Aglaonema Sp.) di Samarinda (Studi Kasus Pada Usaha Agribisnis Salma Shofa Samarinda). Jurnal Ekonomi dan Pembangunan, Vol.6, No.1: 17-23.

Mashud, N., 2012. “Aren sebagai Sumber Pangan”. Prosiding Seminar Nasional Aren. Bogor: Pusat Penelitian dan Pengembangan Perkebunan.

Ruauw, E., J. Baroleh, D. Powa, 2011. “Kajian Pengelolaan Usaha Tani Kelapa di Desa Tolombukan Kecamatan Pasan Kabupaten Minahasa Tenggara". ASE, Vol. 7, No. 2:39-50.

Saleh, Y., 2014. “Analisis Pendapatan Usaha Pengrajin Gula Aren di Desa Tulo'a Kecamatan Bulango Utara Kabupaten Bone Bolango". Jurnal Perspektif Pembiayaan dan Pembangunan Daerah, Vol.1, No.4.

Shinta, A., 2011. Ilmu Usahatani. Malang: Universitas Brawijaya Press.

Supartama, M., M. Antara, dan R. A. Rauf. 2013. “Analisis Pendapatan dan Kelayakan Usahatani Padi Sawah Di Subak Baturiti Desa Balinggi Kecamatan Balinggi Kabupaten Parigi Moutong". Jurnal Agrotekbis, Vol. 1, No 2: 166-172.

Widyawati, N., 2011. Sukses Investasi Masa Depan dengan Bertanam Pohon Aren. Yogyakarta: Lily Publisher.

Wijayanti, T., 2012. "Analisis Pendapatan Usaha Tani Kelapa Sawit di Desa Makmur Jaya, Kecamatan Kongbeng, Kabupaten Kutai Timur". Media Sains, Vol. 4, No 2. 